\title{
CUTANEOUS PETECHIAE IN FATAL CORONARY ARTERY DISEASE
}

\author{
BY \\ L. M. GERLIS \\ From the Department of Pathology, Grimsby General Hospital
}

(RECEIVED FOR PUBLICATION FEBRUARY 6, 1958)

In the clinical recognition of myocardial ischaemia, the nature and distribution of the referred pain which frequently accompanies it are of considerable diagnostic importance. Unfortunately in cases of sudden death there may be no such history and not always is an unequivocal fatal cardiac lesion found, such as a recent or ruptured infarct, or an acute occluding lesion of a coronary artery. In some there is little to indicate why or how the patient actually died, as the only cardiac lesions found are of long standing. The fatal disturbance is often of function rather than of structure and in such cases the post-mortem diagnosis of acute coronary insufficiency is made by implication rather than observation.

In seven necropsies on cases of acute coronary death cutaneous petechiae were observed at sites commonly associated with referred pain of cardiac origin (Fig. 1). No such lesions were obscrved in any deaths not of coronary origin. These petechiae were all outside the area of cutaneous post-mortem hypostasis and in no case was there any evidence of generalized haemorrhagic disease. It is suggested that this sign may be of diagnostic significance in the post-mortem diagnosis of coronary insufficiency. There appears to be no previous description of similar observations in cases of coronary heart disease either before or after death.

\section{Case Reports}

Case 1.-A housewife aged 72 years died two days after admission to hospital in a collapsed state with dyspnoea and pain in the left shoulder. Three weeks previously she had experienced an attack of gripping pain in the retrosternal region. There was no previous history of any other illness.

At necropsy fine recent petechiae were seen over the left deltoid region and in the left submammary region. The heart showed extensive recent infarction involving the whole of the anterior wall of the left ventricle and most of the ventricular septum. The coronary arteries were severely atheromatous, and the first part of the anterior descending branch of the left coronary artery was occluded by a mass of degenerate atheroma.

Case 2.-A man of 64 years who had led a healthy and active life as a pedlar was found dead in bed the day after he experienced a sensation of being unwell, accompanied by pain in the chest and abdomen, although these did not restrict his usual activities.

There was a localized area of fine recent petechiae on the right side of the chest extending as a horizontal band $7 \frac{1}{2} \mathrm{~cm}$. long and $5 \mathrm{~cm}$. wide just below the right nipple and fading out over the right border of the sternum. The lungs showed acute oedema. The heart was not enlarged. A solitary subepicardial petechia was present in the atrioventricular groove near the right cardiac border. The right coronary artery showed a region of atheromatous stenosis at a point $1 \mathrm{~cm}$. from the origin. Distal to this there was a segment of complete occlusion by a thrombus extending for $2 \mathrm{~cm}$., and histological examination showed acute haemorrhagic extravasation into the adventitia overlying this occluded portion. The myocardium showed no evidence of acute infarction.

Case 3.-This 37-year-old blacksmith was found to have an enlarged heart and an atypical bundle-branch block at the age of 29 . In the subsequent two years he had several attacks of "blackout" which were preceded by pain in the tips of the fingers of the left hand which spread up into the left arm, and terminated in unconsciousness. There was no history of convulsive fits. During the last two years of his life he suffered from palpitations.

Three days before death in April, 1953, he had increasing dyspnoea and epigastric pain radiating to the back between the shoulder blades, upwards into both sides of the neck, and down the inner sides of both arms. Clinical examination showed severe shock with cardiomegaly and venous congestion.

At necropsy numerous small recent petechiae were seen over both shoulders and between the shoulder blades. The heart was enormously enlarged, weighing $33 \mathrm{oz}$. (935 g.), this being due to massive hypertrophy and dilatation of the left ventricle. The atria were of normal size. Several superficial recent subepicardial petechiae were present in the atrioventricu- 

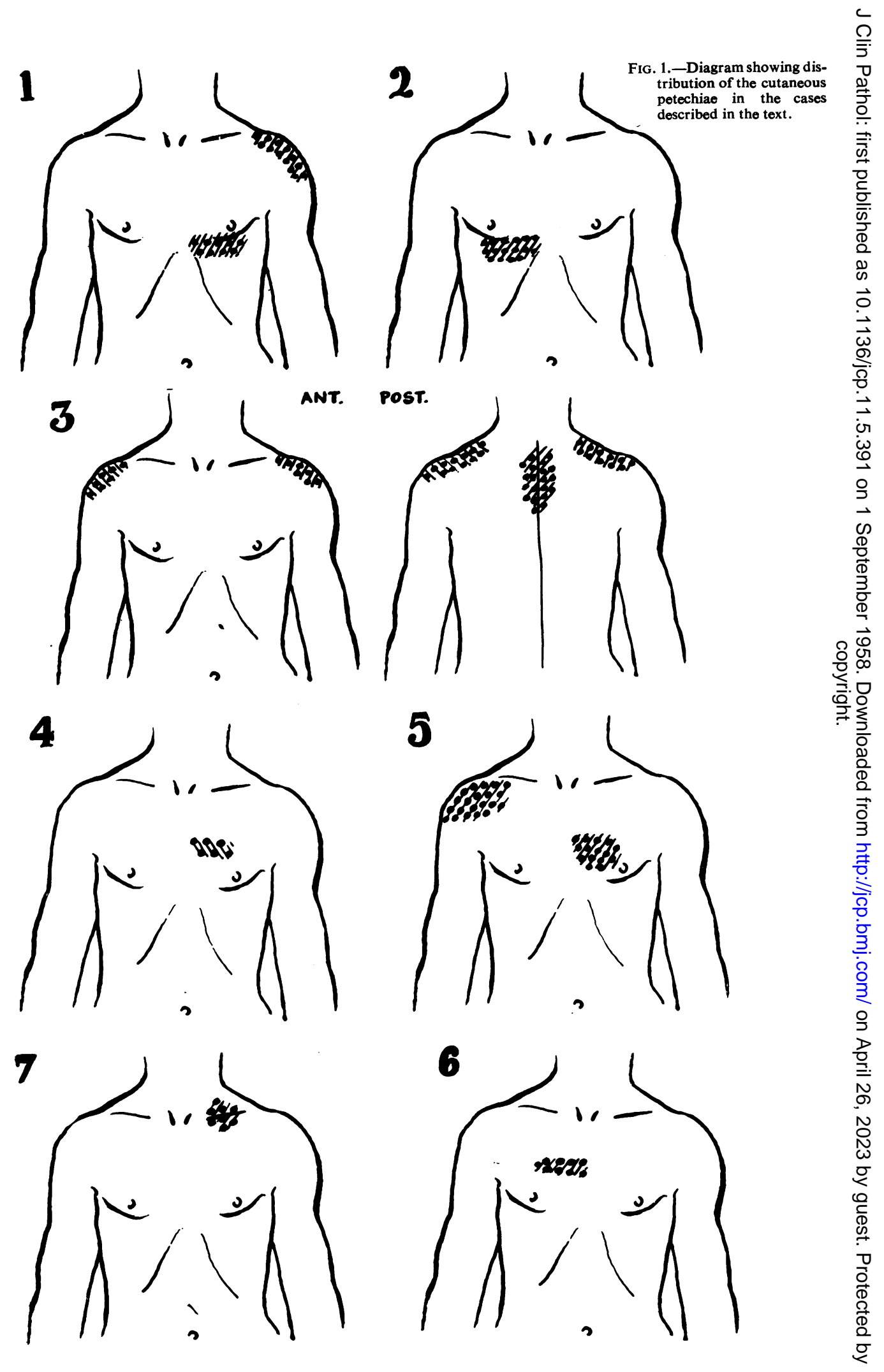
lar groove. There were no septal defects or valvular malformation and no stenosis at the aortic outlet. The aorta showed a moderate generalized hypoplasia. The coronary arteries shared in this hypoplasia; the internal diameters of first parts of both main vessels measured only $2 \mathrm{~mm}$., displaying a marked disproportion to the enormously increased mass of the myocardium.

Case 4. - A woman aged 87 years was found dead in bed having always enjoyed good health until two to three days previously, when she had complained of slight pain in the chest. This caused little distress, and she refused medical attention.

At necropsy six small recent petechiae were seen on the left side of the precordium. Internal examination showed terminal pulmonary oedema and moderate enlargement of the left ventricle. There was generalized coronary atheroma with a zone of recent occlusion in the first part of the right main artery. The myocardium was soft, but there was no actual infarct. Sections of the affected coronary artery showed old organized thrombus in the lumen and recent haemorrhage in the wall.

Case 5.-An 86-year-old man was found dead. There was no previous medical history. There were fine recent petechiae over the left side of the precordium, and over the anterior aspect of the right shoulder. Internal examination showed terminal pulmonary oedema and a moderately enlarged heart. The myocardium was soft and there were patches of interstitial fibrosis. The coronary arteries showed widespread stenosis by calcified atheroma, and there was recent occlusion of the right main artery by thrombus.

Case 6.-For several months this 68-year-old woman had suffered transient attacks of dyspnoea and a sensation of constriction in the chest which had caused very little inconvenience and responded to rest, aspirin, and hot-water bottles. Her final attack began in the usual way, but the sense of constriction became progressively worse and was accompanied by pain. She died before the doctor arrived.

At post-mortem examination there was a transverse, slightly oblique area of erythema over the upper portion of the right side of the precordium which stopped abruptly at the midline. Numerous petechiae were present in this area and there were a few up to $1.5 \mathrm{~cm}$. beyond its well-defined margin (Fig. 2). Internal examination showed extensive calcified atheroma and stenosis of the main coronary arteries with complete occlusion of the anterior descending branch of the left artery from within $1 \mathrm{~cm}$. of its origin. The myocardium was soft, but no infarct was found. Sections of the skin showed that the erythema was due to dilatation of the capillaries of the dermis, and that the petechiae were minute areas of recent haemorrhage.

Case 7.-A seaman aged 64 years was found dead in his bed. There was no available history of previous illnesses. There was a group of about 20

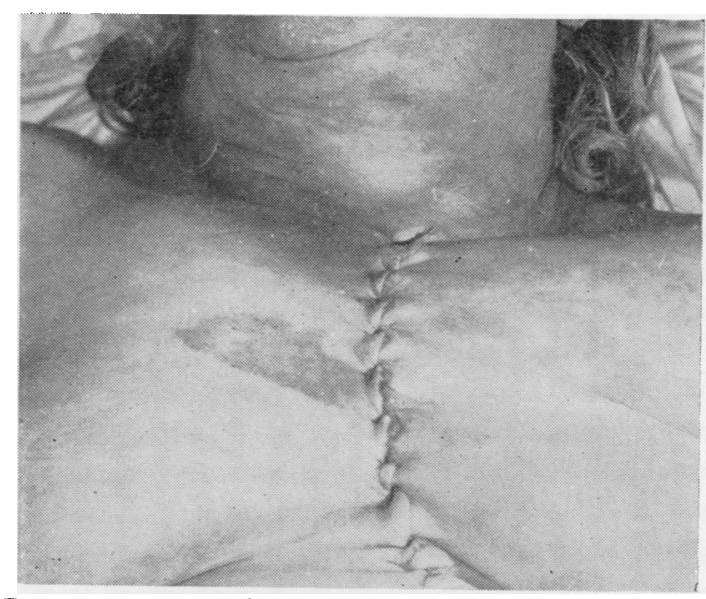

Fig. 2.-Post-mortem photograph of Case 6 showing the well-defined area of precordial erythema and petechiae.

petechiae occupying a circular area approximately $5 \mathrm{~cm}$. in diameter in the skin overlying the central portion of the left clavicle.

Internal examination showed acute terminal congestion and slight oedema of both lungs, these changes being most severe at the bases. Both cardiac ventricles showed slight hypertrophy and there was a small number of subepicardial petechiae in the wall of the left atrium and along the inferior margin of the right ventricle. Both coronary arteries showed marked atherosclerosis with almost complete occlusion of the left coronary artery just proximal to its bifurcation, and of its anterior descending branch. There was an area of haemorrhagic extravasation into the adventitia of the circumflex branch beginning about $3 \mathrm{~cm}$. from its origin and extending for $\frac{1}{2} \mathrm{~cm}$. This was confirmed by histological examination (Figs. 3 and 4). No massive myocardial infarction or fibrosis was present.

\section{Discussion}

Two of these patients (Cases 1 and 3) had been subjected to frequent clinical examinations before death, but in neither case had cutaneous petechiae been noticed, nor have similar lesions been recorded amongst the clinical manifestations of coronary disease.

Although fatal coronary disease is common, these petechiae are rare. Five of the seven cases were from a personally studied series of 360 deaths due to coronary insufficiency in which a search for petechiae was specifically made, giving an incidence of $1.7 \%$.

It is considered that these cutaneous petechiae may be caused by intense efferent stimuli along a sympathetic nerve pathway similar to that involved in referred pain, possibly by agonal relaxation of blood vessels which had been 


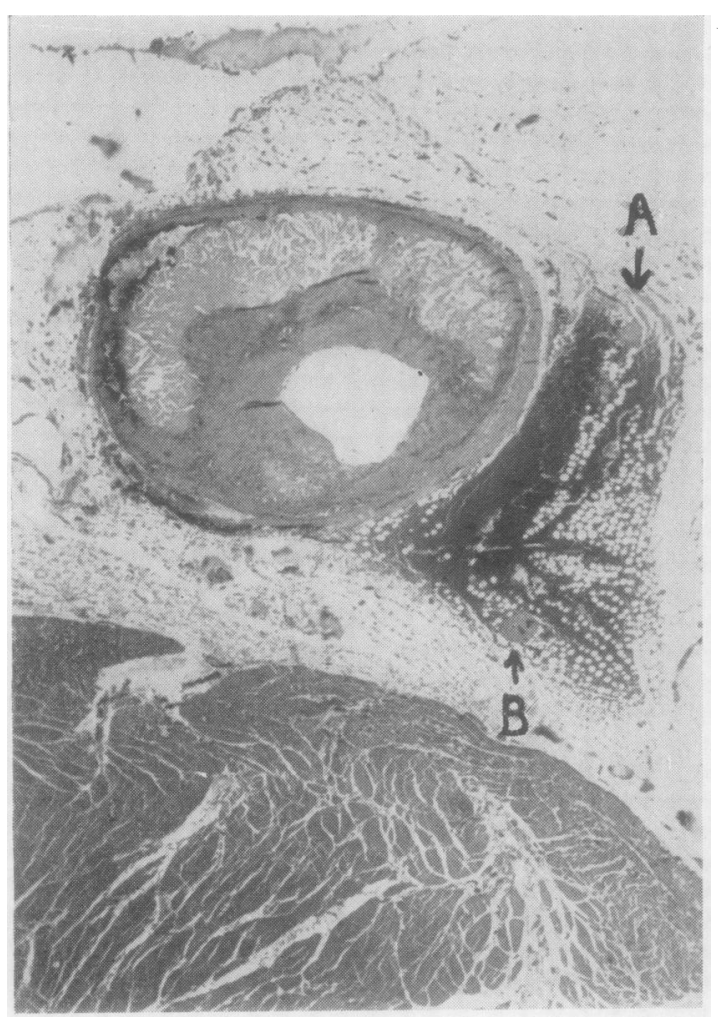

Fig. 3.-Section of the circumflex branch of the left coronary artery from Case 7 showing the adventitial haemorrhage. Involved nerves are indicated at $\mathbf{A}$ and $B$. $(\times 12$. $)$

damaged by prolonged spasm. Peripheral vasoconstriction has been held to be responsible for referred cardiac pain by Roberts (1945) and has been demonstrated by variations of cutaneous temperature (Doret and Ferrero, 1951). An analogous mechanism is known to be responsible for the trophic lesions in the upper limb which are well-recognized clinical sequelae of acute cardiac pain and myocardial infarction (Askey, 1941; Kehl, 1943 ; Johnson, 1943 ; Steinbrocker, Spitzer, and Friedman, 1948; Hilker, 1949; Chitwood, 1950 ; Swan and Henderson, 1951).

Apart from possibly initiating reflexes, which may cause spasm of the peripheral vessels, the coronary arteries themselves are subject to vasospastic stimuli from various organs of the body (von Bergmann, 1932; Greene, 1935; Gilbert, Fenn, and LeRoy, 1940 ; Freedberg, Spiegl, and Riseman, 1944). It is possible that in the cases described in the present series the violent cutaneous reflexes were accompanied by equally violent spasm of the coronary arteries. This may explain why the petechiae have been found only at post-

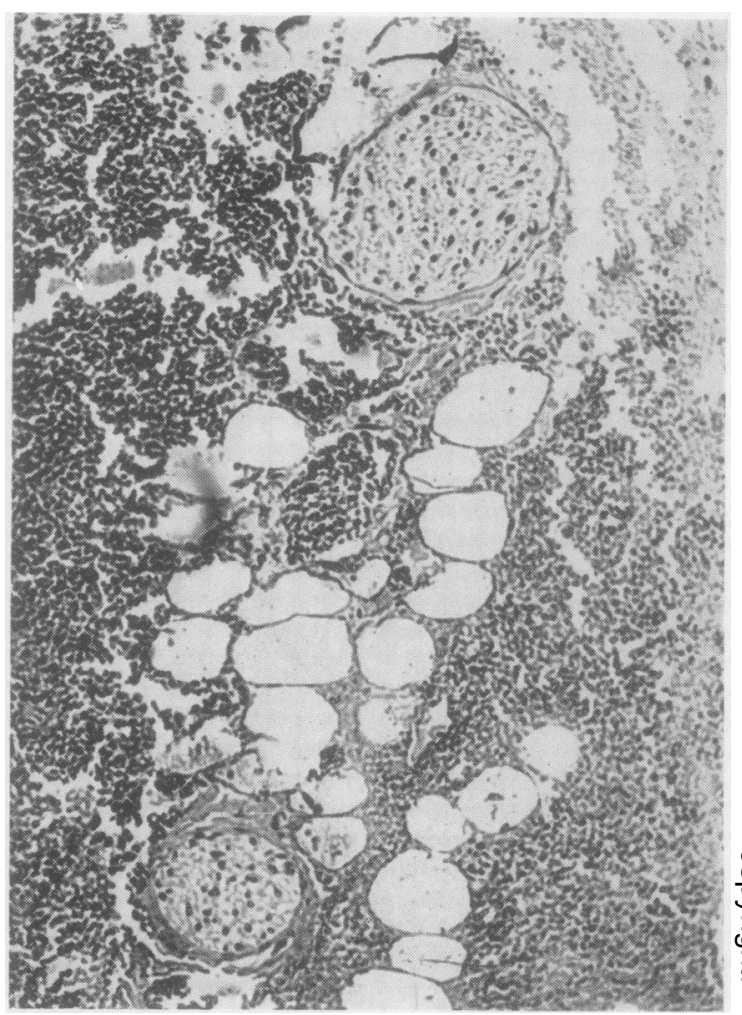

FIG. 4.-The area indicated by arrow $A$ in Fig. $3 \times 150$, showing two adventitial nerves in the area of haemorrhagic extravasation.

morter, examinations, and not in patients who have survived an acute coronary episode.

In four of the seven cases there were haemorrhages directly related to the coronary arteries themselves. In three of these there were haemorrhages in the coronary adventitia and direct involvement of the nerve elements may have played some part in the production of vasospastic reflexes to the skin and coronary arteries (Figs. 3 and 4). However, such haemorrhages are not common in fatal coronary insufficiency. In 100 cases without cutaneous petechiae, only three examples of adventitial haemorrhage were found and the adventitial lesions in the "petechiae" cases were probably an effect rather than a cause, occurring together with the cutaneous lesions by a similar reflex mechanism.

In Case 4 there was subintimal haemorrhage in the wall of the coronary artery, and, if it is considered that this condition may also be caused by nervous reflexes, this may have a bearing on a major mechanism of acute coronary insufficiency. Paterson (1936) first showed the importance of 
subintimal haemorrhage in the pathogenesis of coronary disease, and Wartman (1938) considered it to be the second most common cause of coronary artery occlusion, thrombosis being the first. Expanding subintimal or mural haematomata are held to be responsible for about $10 \%$ of cases of acute coronary occlusion (Lowe, 1950), but in many more cases a small haemorrhage in the wall may play an important role by initiating thrombosis in the arterial lumen. Wartman (1950) found significant haemorrhage in $62 \%$ of a series of 365 cases of fatal coronary occlusion, and Drury (1954) found it in 37 of 58 cases $(68 \%)$. In a personal series of 100 deaths due to coronary disease mural haemorrhage was found in 58 cases.

It is an interesting speculation that, if such haemorrhages can be produced by nervous stimuli, it is possible that anginal pain, not associated with organic coronary occlusion, might in fact cause such occlusion.

\section{Summary}

Seven cases are described in which cutaneous petechiae were found at necropsy on patients who had died of acute coronary insufficiency. These petechiae occurred in areas commonly associated with referred cardiac pain.

It is suggested that the presence of such localized petechiae is supporting evidence of acute coronary insufficiency, particularly in those cases where the coronary arteries themselves show no recent culpable organic lesion. In four of the cases haemorrhagic lesions were found in direct relationship to the coronary arteries. The mechanism is discussed and the possible role of reflex activity in the aetiology of subintimal coronary haemorrhages is considered.

I wish to thank Dr. J. D. H. Millar and Dr. M. Steel for permission to publish clinical details of their cases, and also Dr. J. M. Johnstone for the post- mortem findings on Case 7 and for his advice on the preparation of this paper.

\section{Addendum}

Since writing this paper the following additional case has been encountered.

A heavily built man aged 67 years was sitting quietly in his home watching television; he bent forward to place some wood on the fire, sat back in his chair and died suddenly and quietly.

At necropsy there was a small group of minute recent petechiae up to $0.5 \mathrm{~cm}$. in diameter over the front of the left shoulder in an ill-defined horizontal band $5 \mathrm{~cm}$. long and $1 \mathrm{~cm}$. wide.

The heart was moderately enlarged $(450 \mathrm{~g}$.) and there was an extensive area of recent myocardial infarction involving the distal half of the anterior wall of the left ventricle and the adjacent portion of the interventricular septum.

The coronary arteries showed only moderate atheroma, except for an area of localized occlusion of the anterior descending branch of the left artery at a point of $3.5 \mathrm{~cm}$. from its origin. Sections of this region showed considerable stenosis by a lipoid plaque in which there was recent haemorrhage which communicated with a recent thrombus that occluded the lumen of the vessel.

\section{REFERENCES}

Askey, J. M. (1941). Amer. Heart J., 22, 1.

Bergmann, G. von (1932). Dtsch. med. Wschr., 58, 605.

Chitwood, W. R. (1950). New Engl. J. Med., 243, 813.

Doret, J. P., and Ferrero, R. (1951). Cardiologia (Basel), $19,80$.

Drury, R. A. B. (1954). J. Path. Bact., 67, 207.

Freodberg, A. S., Spiegl, E. D., and Riseman, J. E. F. (1944). Amer Heart $J ., 27,611$.

Gilbert, N. C., Fenn, G. K., and LeRoy, G. V. (1940). J. Amer. med. Ass., 115, 1926.

Greene, C. W. (1935). Amer. J. Physiol., 113, 399.

Hilker, A. W. (1949). Ann. intern. Med., 31, 303.

Johnson, A. C. (1943). Ibid., 19, 433.

Kehl, K. C. (1943). Ibid., 19, 213.

Lowe, T. E. (1950). Studies in Pathology, p. 81. Cambridge University Press, London.

Paterson, J. C. (1936). Arch. Path. (Chicago), 22, 313.

Roberts, J. T. (1945). Med. Ann. D.C., 14, 483

Steinbrocker, O., Spitzer, N., and Friedman, H. H. (1948). Ann. intern. Med., 29, 22 .

Swan, W. G. A., and Henderson, C. B. (1951). Brit. Heart J., 13, 68. Wartman, W. B. (1938). Amer. Heart J., 15, 459. (1950). Studies in Pathology, p. 95 . Cambridge University
Press, London. 